\title{
Research Paper: The Effect of Five-Toed Shoes on Electromyographic Activity of Leg Muscles During Stance Phase of Running
}

\author{
Maryam Razaghzadeh ${ }^{1}$, Mehrdad Anbarian ${ }^{2}$ Hamideh Khodaveisi $^{3^{*}}$ \\ 1. Department of Physical Education, Borujerd Branch, Islamic Azad University, Borujerd, Iran. \\ 2. Department of Sport Biomechanics, Faculty of Sport Sciences, Bu-Ali Sina University, Hamedan, Iran. \\ 3. Department of Physical Education, Faculty of Human Sciences, Hamedan Branch, Islamic Azad University, Hamedan, Iran.
}

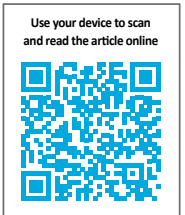

Citation: Khodaveisi H, Razaghzadeh M, Anbarian M. The Effect of Five-Toed Shoes on Electromyographic Activity of Leg Muscles During Stance Phase of Running. Physical Treatments. 2017; 6(4):227-232. https://doi.org/10.18869/nrip.ptj.6.4.227

: https://doi.org/10.18869/nrip.ptj.6.4.227

Article info:

Received: 12 Jun. 2016

Accepted: 08 Oct. 2016

Keywords:

Five-toed shoe,

Electromyography,

Running, Leg muscles

\section{A B S T R A C T}

Purpose: The current study aimed at evaluating the effect of 5-toed shoes on electromyographic activity of leg muscles during the stance phase of running.

Methods: The current semi-experimental study recorded the electromyographic activity of tibialis anterior, soleus, gastrocnemius lateralis, and medialis muscles of 15 healthy male students (mean age: $24.5 \pm 3.4$ years, mean height: $177.6 \pm 5.8 \mathrm{~cm}$, and mean weight: $75.7 \pm 8.9 \mathrm{~kg}$ ) during the stance phase of running in barefoot and shod (5-toed shoes) conditions. Paired sample $t$ test was used for statistical analysis with SPSS19.

Results: In shod running, electromyographic activity of tibialis anterior during loading response phase $(\mathrm{P}=0.001)$ and electromyographic activity of soleus $(\mathrm{P}=0.002)$ and medial gastrocnemius $(\mathrm{P}=0.004)$ during propulsion phase were significantly higher, compared with the barefoot running; there was no significant difference in gastrocnemius lateralis muscle between both conditions $(\mathrm{P}>0.05)$.

Conclusion: According to the current study findings, using 5-toed shoes could increase electromyographic activity of leg muscles during the stance phase of running.

\section{Introduction}

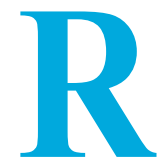

unning is a basic skill of displacing and executing sports activities [1]. Leisure runners are the vulnerable groups and it is shown that $19.4 \%$ to $79.3 \%$ of individuals participating in activities including running experience chronic injuries every year [2].
Recently barefoot running is of great interest in sports clinics [3]. Some researchers reported that barefoot running results in reduction of chronic injuries in runners [4]. This can be due to the fact that in barefoot running, heel-toe pattern is used, which leads to reduction of contact forces on organs from ground or land surface [5].

Since foot is the most important tool of interaction between the ground and body, the performance structure of

\footnotetext{
* Corresponding Author:

Hamideh Khodaveisi, PhD

Address: Department of Physical Education, Faculty of Human Sciences, Hamedan Branch, Islamic Azad University, Hamedan, Iran.

Phone: +98 (918) 8156787

E-mail: khodaveisi_hamideh@yahoo.com
} 
foot influences the pattern of transitional movements [6, 7]. Any deviation in feet can transfer its effect on joints and upper extremities in a chain format. Modification of forces applied to foot is one of the roles of these shoes [1]. Recently, in biomechanics studies, focus on barefoot running and the number of runners who tend to run on barefoot and 5-toed shoes were increasing, which shows that barefoot running reduces the possible damages on joints and muscles followed by the reduction of velocity and intensity of foot contact with ground by the musculoskeletal system. The study showed that running on barefoot and 5-toed shoes imposes less pressure on the body; in addition, eccentric activity of quadriceps femoris muscle in barefoot is reduced, compared with the normal shoes.

There are different shoes in the market such as instable shoes; 5-toed shoes and the shoes designed for different sports such as running [8-10]. The purpose of using instable shoes is involving the muscles more, and as a result, strengthening the muscles and preventing their weaknesses in long-term that play an important role in kinematic and kinetic changes [11, 12]. Five-toed shoes are already available in the market.

There are few researches to determine the merits and demerits of 5-toed shoes [3, 13]. For example, it is reported that there is no difference in the sense of joints after running between barefoot and 5-toed shoes [13]. Also, the force applied to Achilles tendon in barefoot running is greater than that of 5-toed shoes running, while the knee extension moment in running in 5-toed shoes is greater than that of barefoot running [3].

Because of the important role of the shoes in comfort and level of pressures applied to joints, it is necessary to study the role of such shoes. The current study aimed at investigating the electromyographic activity of leg muscles in loading response sub-phase and running progress in barefoot and 5-toed shoes.

\section{Materials and Methods}

The current quasi-experimental study was conducted in 2016. The sample constituted 15 healthy male students with the mean age of 24.5 years, mean height $177.6 \mathrm{~cm}$, and mean weight $75.7 \mathrm{~kg}$. The inclusion criteria of the study were no history of surgery, fracture, burning, damage, or severe trauma in lower extremities, as well as no artificial organs in thigh, knee, and ankle, in addition to no medical shoes, diabetes, and specific diseases.

Biomonitor ME6000® (Finland) was used to record the electromyographic activity of muscles. The device can record the activity of 16 muscles simultaneously. The electrodes are adhesive and disposable, and can be attached to the positive and negative electrodes of each channel in a electromyography (EMG) device. It also contains specific gel to reduce the skin resistance and receive the muscle electrical activity and transfer to EMG device. The shoes used in the current study were the 5-toed shoes (Figure 1)

The procedures were followed when the subjects referred to the lab. First, the redundant hair on front foot was removed and the skin was cleaned with cotton and alcohol. Then, the adhesive AG-Agcl electrodes containing conduction gel were installed on the selected muscles based on SENIAM recommendations to reduce the skin electrical resistance and transfer the electrical impulses [14].

The earth electrode was placed on the tibia bone. Surface EMG signals were collected with sampling frequency of $1000 \mathrm{HZ}$ and passed through a bypass filter 8 to $450 \mathrm{HZ}$. After installing the electrodes, the subjects were asked to move in a direct path of $15 \mathrm{~m}$ at the determined speed (Figure 2) to have a natural running (3 to 5 meters) and prepare themselves for the main test. Three trials were recorded for each situation (barefoot and shed). The muscles were soleus, medial, lateralis gastrocnemius, and tibialis anterior, and the moving speed $(3 \mathrm{~m} / \mathrm{s})$ was controlled by a chronometer. In the current study, the stance phase of running was divided into loading and propulsion sub-phases. The values of RMS were normalized in each sub-phase by the Maximal Voluntary Isometric Contraction (MVIC) method.

Statistical analysis was performed with SPSS version 19. The Shapiro-Wilk test was applied to assess the normal distribution of the data. The paired t test was used to compare the variables between different positions. $\mathrm{P}<0.05$ was considered as the level of significance.

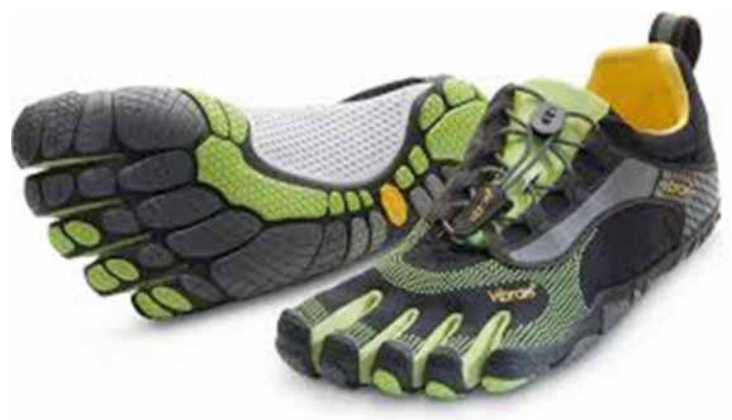

PHYSICAL TREA † MENTS

Figure 1. The shoes used in the study 


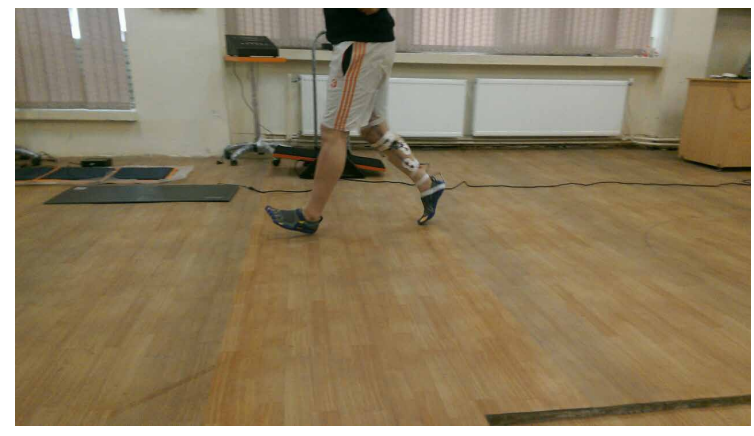

PHYSICAL TREA T MENTS

Figure 2. Running path and EMG recording

\section{Results}

The results of comparing tibialis anterior muscle activity between 5-toed shoes and barefoot in the sub-phase of loading response showed a significant difference in the mean activity of tibialis anterior muscle between the cases $(\mathrm{P}=0.001)$. The muscle activity of tibialis anterior was higher in the 5-toed shoes than barefoot (Table 1). The means of electromyographic activity of soleus muscle, medial, and lateralis gastrocnemius in barefoot and 5-toed shoes in the sub-phase of loading response of running stance showed no significant difference (Table 1).

Findings showed no significant difference between muscle activity of tibialis anterior and lateralis gastrocnemius in both cases; while the activity of medial gastrocnemius and soleus muscles when using 5-toed shoes was significantly greater than that of the barefoot in the propulsion sub-phase (Table 2).

\section{Discussion}

The current study aimed at investigating the electromyographic activity of leg muscles in loading response and running propulsion sub-phases in barefoot and 5 -toed shoes runners. The activity of tibialis anterior muscle in 5-toed shoes in loading response sub-phase was higher than that of the barefoot case. Tibialis anterior muscles are contracted extroversive in loading response in toe-heel pattern to prevent quick contact of foot with the ground [15]. Therefore, the greater activity of this muscle in this sub-phase for 5-toed shoes may cause more absorption of energy in ankle joint and reduction of contact forces in foot striking the ground. The toe-heel running pattern in shoe and barefoot runners can be the reason of greater activity of tibialis anterior muscle [16-18]. There was no significant difference in the mean electromyographic activity of soleus, medial, and lateralis gastrocnemius muscles between both cases in the loading sub-phase of running stance.

The current study findings showed that in the propulsion sub-phase there was no significant difference in the mean activity of tibialis anterior and lateralis gastrocnemius muscles for the 5-toed shoes and barefoot, while the activity of medial gastrocnemius and soleus muscles in 5-toed shoes was significantly greater than that of the barefoot in the propulsion sub-phase. These results were not consistent with those of Sinclair's research, which stated that the force applied on Achilles tendon in running with barefoot is less than that of the 5-toed shoes [3].

Table 1. Modified RMS comparison of leg muscles in the running loading response sub-phase in barefoot and five-toed shoes

\begin{tabular}{ccccc}
\hline Muscle & Barefoot & Five-Toed Shoes & t & P \\
\hline Tibialis anterior & $67.7 \pm 16.1$ & $98.3 \pm 24.7$ & 4.477 & $0.001^{*}$ \\
\hline Soleus & $47.5 \pm 24.2$ & $54.9 \pm 28.7$ & 1.708 & 0.110 \\
Medial gastrocnemius & $44.5 \pm 14.5$ & $51.5 \pm 20.2$ & 1.725 & 0.107 \\
\hline Lateralis gastrocnemius & $47.3 \pm 21.0$ & $52.4 \pm 20.6$ & 1.102 & 0.289 \\
\hline$*: P<0.05$ & & & PHYSICAL TREA MENTS
\end{tabular}

Table 2. Comparison of modified RMS in calf muscles in propulsion in five-toed shoes and barefoot runners

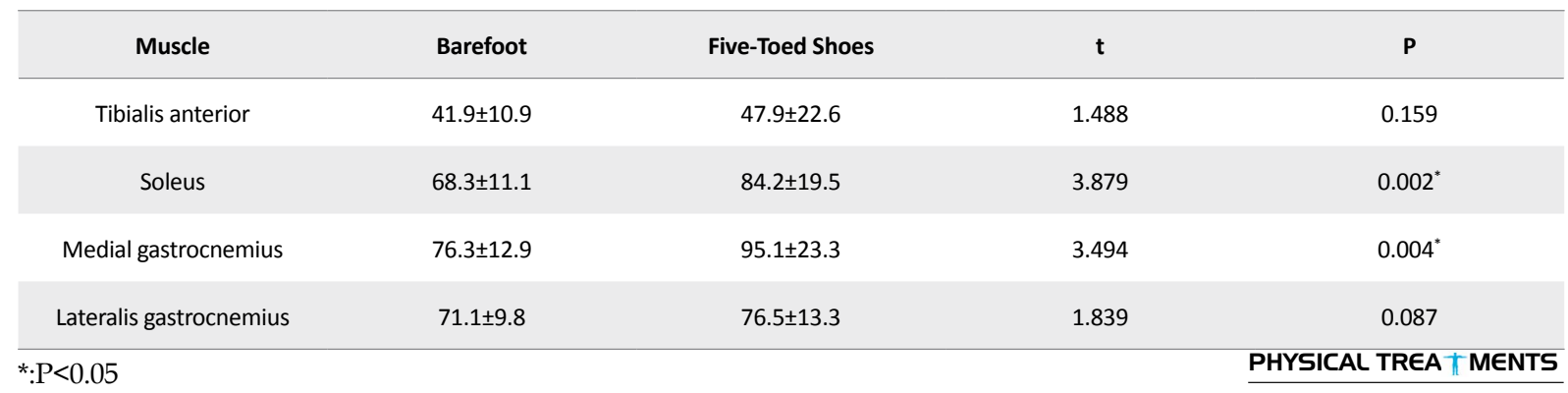


The likely reason can be that the greater electromyographic activity of muscles in dynamic movements does not show the greater force produced by muscles [19] and the relationship of muscle activity domain with the produced force is linear only in isometric contraction [20, 21]. Thus, another reason can be toe-heel running pattern for greater force on Achilles tendon in barefoot running, although more research is needed to prove it.

According to the results of most researches, the purpose of shoe design is to increase muscle activity and prevent muscle weaknesses in daily activities such as running and walking $[12,22]$. Regarding the current study results, it can be said that 5-toed shoes can increase the leg muscles activities such as tibialis anterior, medial, and lateralis gastrocnemius in running stance, in addition to protection of foot against damage from contact with external bodies. Therefore, they are suitable to strengthen the leg muscles in daily activities.

The role of medial gastrocnemius muscles such as ankle plantar flexor in running is to stabilize the ankle and knee and control tibialis bone rotation to reduce the damage. It seems that in 5-toed shoes, due to the increase of medial gastrocnemius activity, the possible damages on ankle and knee are less. Yet, the effect of these shoes on the activity of other extremities and trunk muscles as well as other kinematic and kinetic variables should be studied to explain the biomechanical features of these shoes.

Using the 5-toed shoes can increase the activity of tibialis anterior muscle in loading response and also increase the activity of medial gastrocnemius and soleus muscles in the propulsion sub-phase. It seems that running in 5-toed shoes had more efficiency to activate leg muscles, compared with normal shoes.

\section{Acknowledgements}

This study was extracted from MSc. thesis of the first author, Maryam Razaghzadeh, in the Department of Physical Education, Borujerd Branch, Islamic Azad University, Borujerd. The authors would like to thank all the participants in the study

\section{Conflict of Interest}

All authors certify that this manuscript has neither been published in whole nor in part nor being considered for publication elsewhere. They have no conflicts of interest to declare.

\section{References}

[1] Nigg BM. Biomechanics of running shoes. Journal of Biomechanics. 1988; 21(10):887. doi: 10.1016/0021-9290(88)90120-0

[2] Van Gent RN, Siem D, van Middelkoop M, van Os AG, Bierma-Zeinstra SMA, Koes BW, et al. Incidence and determinants of lower extremity running injuries in long distance runners: A systematic review. British Journal of Sports Medicine . 2007; 41(8):469-80. doi: 10.1136/bjsm.2006.033548

[3] Sinclair J. Effects of barefoot and barefoot inspired footwear on knee and ankle loading during running. Clinical Biomechanics. 2014; 29(4):395-9. doi: 10.1016/j.clinbiomech.2014.02.004

[4] Lieberman DE, Venkadesan M, Werbel WA, Daoud AI, D'Andrea S, Davis IS, et al. Foot strike patterns and collision forces in habitually barefoot versus shod runners. Nature. 2010; 463(7280):531-5. doi: 10.1038/nature08723

[5] Sinclair J, Greenhalgh A, Brooks D, Edmundson CJ, Hobbs SJ. The influence of barefoot and barefoot-inspired footwear on the kinetics and kinematics of running in comparison to conventional running shoes. Footwear Science. 2013; 5(1):45-53. doi: 10.1080/19424280.2012.693543

[6] Zifchock RA, Davis I. A comparison of semi-custom and custom foot orthotic devices in high and low arched individuals during walking. Clinical Biomechanics. 2008; 23(10):128793. doi: 10.1016/j.clinbiomech.2008.07.008

[7] Ledoux WR, Shofer JB, Ahroni JH, Smith DG, Sangeorzan BJ, Boyko EJ. Biomechanical differences among pes cavus, neutrally aligned, and pes planus feet in subjects with diabetes. Foot \& Ankle International. 2003; 24(11):845-50. doi: $10.1177 / 107110070302401107$

[8] Lussiana T, Hébert-Losier K, Mourot L. Effect of minimal shoes and slope on vertical and leg stiffness during running. Journal of Sport and Health Science. 2015; 4(2):195-202. doi: 10.1016/j.jshs.2013.09.004

[9] Bonacci J, Saunders PU, Hicks A, Rantalainen T, Vicenzino B (Guglielmo) T, Spratford W. Running in a minimalist and lightweight shoe is not the same as running barefoot: A biomechanical study. British Journal of Sports Medicine . 2013; 47(6):387-92. doi: 10.1136/ bjsports-2012-091837

[10] Ridge ST, Johnson AW, Mitchell UH, Hunter I, Robinson E, Rich BSE, et al. Foot bone marrow edema after a 10-week transition to minimalist running shoes. Medicine \& Science in Sports \& Exercise. 2013; 45(7):1363-8. doi: 10.1249/ mss.0b013e3182874769

[11] Boyer KA, Andriacchi TP. Changes in running kinematics and kinetics in response to a rockered shoe intervention. Clinical Biomechanics. 2009; 24(10):872-6. doi: 10.1016/j. clinbiomech.2009.08.003

[12] Landry SC, Nigg BM, Tecante KE. Standing in an unstable shoe increases postural sway and muscle activity of selected smaller extrinsic foot muscles. Gait \& Posture. 2010; 32(2):215-9. doi: 10.1016/j.gaitpost.2010.04.018

[13] Squadrone R, Gallozzi C. Effect of a five-toed minimal protection shoe on static and dynamic ankle position sense. The Journal of Sports Medicine and Physical Fitness. 2011; 51(3):401-8. PMID: 21904278 
[14] Hermens HJ, Freriks B, Merletti R, Stegeman D, Blok J, Rau $\mathrm{G}$, et al. European recommendations for surface electromyography. Roessingh Research and Development. 1999; 8(2):13-54.

[15] Von Tscharner V, Goepfert B, Nigg BM. Changes in EMG signals for the muscle tibialis anterior while running barefoot or with shoes resolved by non-linearly scaled wavelets. Journal of Biomechanics. 2003; 36(8):1169-76. doi: 10.1016/ s0021-9290(03)00086-1

[16] De Wit B, De Clercq D, Aerts P. Biomechanical analysis of the stance phase during barefoot and shod running. Journal of Biomechanics. 2000; 33(3):269-78. doi: 10.1016/s00219290(99)00192-x

[17] Divert C, Mornieux G, Baur H, Mayer F, Belli A. Mechanical comparison of barefoot and shod running. International Journal of Sports Medicine. 2005; 26(7):593-8. doi: 10.1055/s2004-821327

[18] Squadrone R, Gallozzi C. Biomechanical and physiological comparison of barefoot and two shod conditions in experienced barefoot runners. Journal of Sports Medicine and Physical Fitness. 2009; 49(1):6-13. PMID: 19188889

[19] Kamen G, Gabriel D. Essentials of electromyography: Human Kinetics. Canada: Human Kinetics; 2010.

[20] Winter DA. Biomechanics and motor control of human movement. New Jersey: John Wiley \& Sons; 2009. doi: 10.1002/9780470549148

[21] Disselhorst-Klug C, Schmitz-Rode T, Rau G. Surface electromyography and muscle force: Limits in sEMG-force relationship and new approaches for applications. Clinical Biomechanics. 2009; 24(3):225-35. doi: 10.1016/j.clinbiomech.2008.08.003

[22] Romkes J, Rudmann C, Brunner R. Changes in gait and EMG when walking with the Masai Barefoot Technique. Clinical Biomechanics. 2006; 21(1):75-81. doi: 10.1016/j.clinbiomech.2005.08.003 
